Formation of $\mathrm{Ag}$ nanoparticles on $\boldsymbol{\beta}-\mathrm{Ag}_{2} \mathrm{WO}_{4}$ through electron beam irradiation: a synergetic computational and experimental study

Roman A. Roca, ${ }^{\dagger}$ Amanda F. Gouveia, ${ }^{\dagger}$ Pablo S. Lemos, ${ }^{\dagger}$ Lourdes Gracia, ${ }^{\dagger}$ Juan Andrés, ${ }^{*}{ }^{*}$ and Elson Longo ${ }^{\dagger}$

${ }^{\dagger}$ CDMF-UFSCar-Universidade Federal de São Carlos, P.O. Box 676, CEP, $13565-$ 905 São Carlos-SP, Brazil.

${ }^{\ddagger}$ Department of Analytical and Physical Chemistry, University Jaume I (UJI), Castelló 12071, Spain.

Supporting Information 


\section{Captions for Figures}

Figure S1. FE-SEM images of $\beta-\mathrm{Ag}_{2} \mathrm{WO}_{4}$ microcrystals.

Figure S2. (a) Bond lengths $(\mathrm{Ag}-\mathrm{O}$ and $\mathrm{Ag}-\mathrm{Ag})$ and (b) angles $(\mathrm{O}-\mathrm{Ag}-\mathrm{O})$ as a function of the number of electrons in $\beta-\mathrm{Ag}_{2} \mathrm{WO}_{4}$.

Figure S3. Bader charge densities of $\mathrm{Ag} 1$, and $\mathrm{Ag} 2$ centers for both $\left[\mathrm{AgO}_{6}\right]$ and $\left[\mathrm{AgO}_{5}\right]$ clusters as a function of the number of electrons in $\beta-\mathrm{Ag}_{2} \mathrm{WO}_{4}$, where $q(\Omega)$ represents the difference between the number of valence electrons and calculated charge density. 
Figures

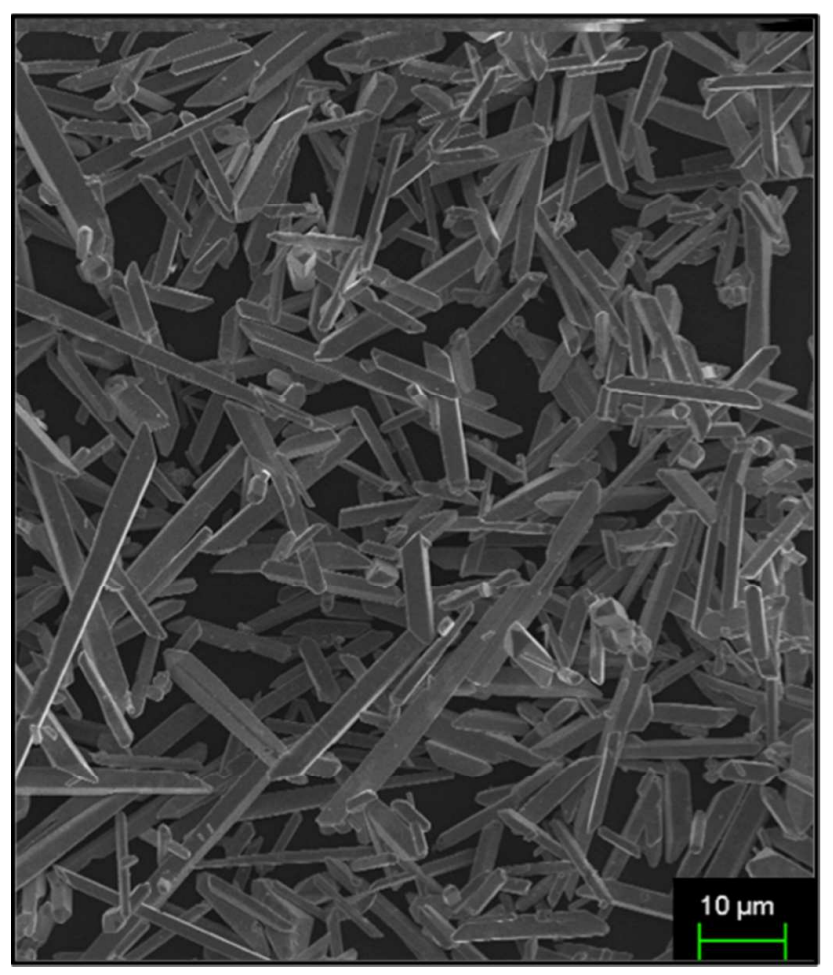

$<$ Figure S1 > 


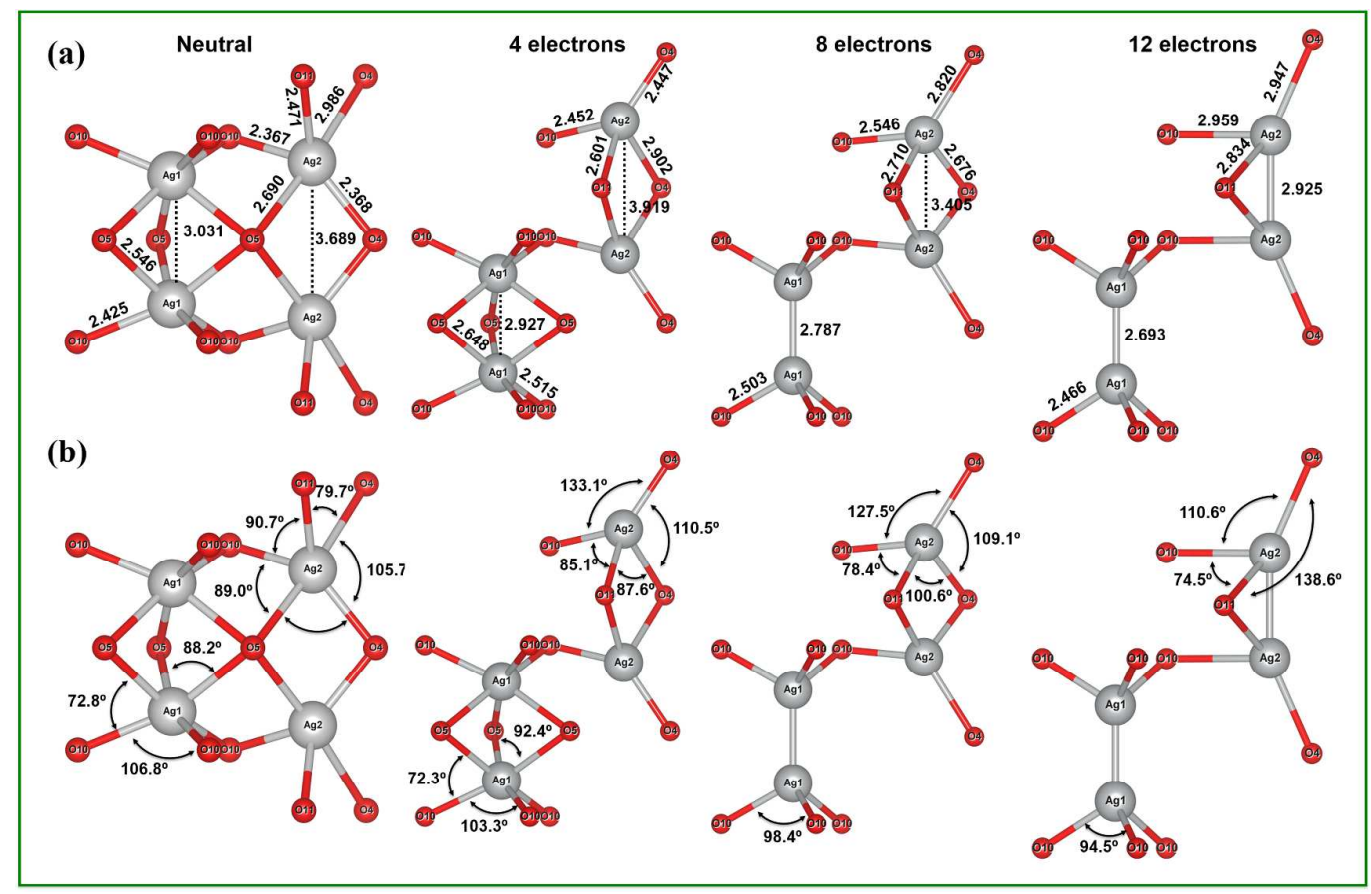

$<$ Figure S2 $>$

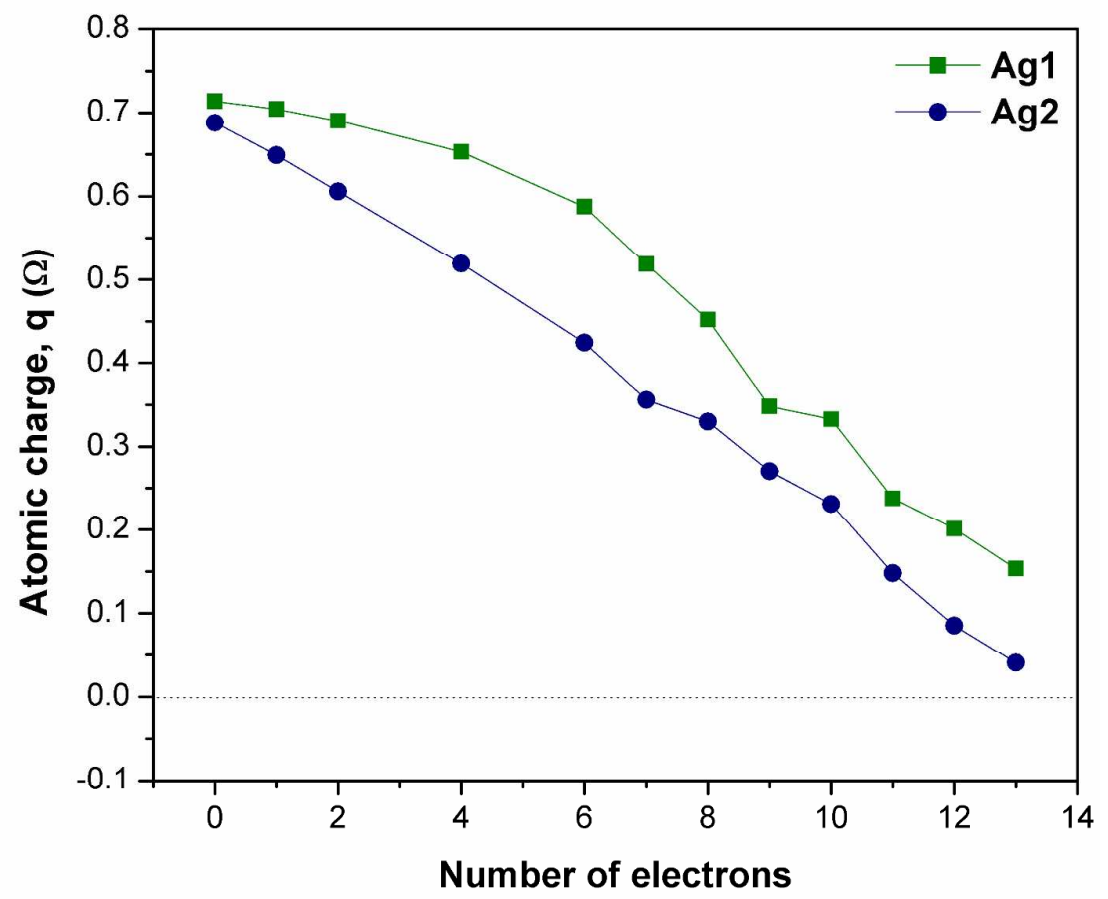

$<$ Figure S3 $>$ 